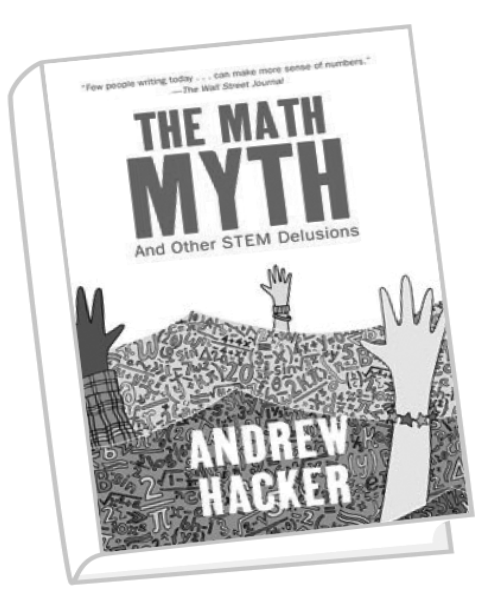

\author{
A Review by David M. Bressoud
}

\author{
The Math Myth and Other STEM Delusions \\ Andrew Hacker \\ The New Press, 2016 \\ US\$15.57, 240 pages \\ Hardcover ISBN-13: 978-1-6209-7068-3
}

While there is much to dislike about Andrew Hacker's book, it is too easy, especially for the audience of these Notices, to dismiss it and ignore the underlying issues. This book and similar attacks on the role of algebra arise from real structural problems within mathematics education.

The fundamental problem is that the general population has a very poor conception of mathematics. Hacker plays on this by identifying algebra with words that sound scary: "azimuths and asymptotes" and "radical notations and elliptical equations." Building on painful memories of drill in rote procedures that made no sense, he finds a ready audience for his message that this is all a great conspiracy of the "math mandarins," those research mathematicians at top-tier universities who are subjecting the general population to their distorted view of what a proper education should be.

\section{Issues of Access}

After his chapter "Will plumbers need polynomials?" Hacker gives an unattributed quote that is quite insightful: "In other nations, such as Germany and Switzerland, it would be absurd to say that all sixteen-year-olds should have to learn the same stuff." It would be, because the Eu-

David Bressoud is DeWitt Wallace Professor of Mathematics at Macalester College. His email address is bressoud@macalester . edu.

For permission to reprint this article, please contact:

reprint-permission@ams.org.

DOI: http://dx.doi.org/10.1090/noti1442 ropean expectation is that university education is reserved for the elite. Their secondary schools distinguish between those they are preparing for university and those who receive skills training that prepares them for employment but blocks them from access to universities. Post-World War II, the American belief has been that university education should be available to all. A corollary of this belief is that everyone should enroll in the courses that will enable further study.

Hacker wants it all. He wants to see secondary programs that focus on targeted workplace skills while preparing everyone for postsecondary education. I am not willing to claim that this is a circle that cannot be squared, but building such an educational system is going to be far harder than he implies. The sad fact is that for many of our students our educational system delivers neither.

The blame cannot be placed entirely at the foot of mathematics. While over 60 percent of entering community college students need remediation in mathematics, about half of these also need remediation in reading, a far more serious impediment. Nevertheless, mathematics is a stumbling block for many students who could otherwise succeed. What high school mathematics do they really need?

This is an important question that requires a thoughtful response. On page 8 , Hacker admits that "basic algebra is definitely necessary for everyone." Where he draws the line is at what he calls "advanced algebra," which is, in fact, Algebra 2. According to the Common Core State Standards for Mathematics, this is the course where, among other skills, students are expected to learn to perform arithmetic operations on polynomials and understand the connections between their zeros and factors; construct and compare linear, quadratic, and exponential models; understand the general role of functions in modeling a 
relationship between two quantities; and come to see trigonometric functions as models of periodic phenomena. These are all useful understandings, even for plumbers, and essential for those who would seek a STEM career.

Part of the problem is that a student's experience of high school mathematics is so often built on a poor comprehension of any mathematics. Mark Green has reflected on this problem in words that express my own ambivalence:

You have a danger of people being limited throughout their lives by what math they got early on-or didn't. There's a lot of stuff that uses Algebra 2, and students who don't take it may be unaware that they are limiting their options later on. On the other hand, it's much better to have someone who genuinely understands modeling and quantitative reasoning and has a feeling for statistics than someone who took an Algebra 2 class but is totally bewildered by it. [1, p. 20]

The best solution seems to be an expectation that all students should take Algebra 2, combined with serious work to ensure that it is a meaningful experience, while recognizing that there will be students for whom an alternative would be more useful and merciful. It is in how we can make Algebra 2 more meaningful that I have my most violent disagreement with Hacker. He has totally mischaracterized the Common Core State Standards for Mathematics.

\section{The True Core of the Common Core}

Hacker presents the Common Core as a rigid set of lesson plans. In reality, the Common Core is not even a curriculum. It is a set of standards, a description of what students should understand and be capable of doing by the end of each grade through middle school. It is based on the best research available in mathematics education to determine what skills and abilities should be mastered by what grade if students are to be prepared for the next set of challenges and to stay on track to have completed Algebra 2 by the end of grade 12 .

It is a framework that emphasizes flexibility. Nowhere is this clearer than in its treatment of high school mathematics, which is not laid out hierarchically. Common Core describes big domains of high school mathematics-Number and Quantity, Algebra, Functions, Modeling, Geometry, and Statistics and Probability-and then leaves it to the districts to figure out how to structure this instruction. The emphasis is not on a list of topics but on what it means to do mathematics. Absolutely essential are the Practice Standards: making sense of problems and persevering in solving them, reasoning abstractly and quantitatively, constructing viable arguments and criticizing those of others, modeling, using tools strategically, attending to precision, looking for and using structure, and looking for and expressing regularity in repeated reasoning. I cannot imagine that any of these are characteristics Hacker would not wish for his own numeracy course. It is because of this flexibility and recognition of what is truly essential that the National Council of Teachers of Mathematics, the professional society of and for pre $\mathrm{K}-12$ teachers of mathematics, has so strongly endorsed and supported the Common Core.

This is not to say that the Common Core is without problems. Standards are useless without a means of assessing whether you are meeting them, hence the development of two national tests: Smarter Balanced and PARCC. Having worked for six years on the AP Calculus exams, I know how difficult it is even in that tightly constrained situation to come up with good questions that meaningfully assess student knowledge and abilities. To try to accomplish this across the varied scene of our national public education while honestly measuring student capabilities under the practice standards of the Common Core is nigh impossible.

I hate to see Smarter Balanced or PARCC used for highstakes testing. That puts unneeded pressure on teachers and invites the very practice Common Core is trying to avoid, a mentality of drilling for the test. However, we will not be able to determine how effectively this program is being implemented without some form of accountability. Finding the right balance is one of the places where bright minds, patience, and nuance are required. Populist cries that Common Core is a big government (or big business) takeover of public education are not helpful.

\section{Quantitative Literacy, a Point of Convergence}

I now come to the place where I am closest to agreeing with Hacker, the question of what mathematics should be required at the postsecondary level. There is little point in forcing college students to retread the landscape of confusion that they left in high school unless these are skills and abilities needed for their chosen careers. I am proud that I was instrumental in the development of a successful quantitative literacy program at Macalester College for which the only mathematics course that fully satisfies this requirement is one in statistical modeling with emphasis on exploration and interpretation of real data. Quantitative literacy, or numeracy, is helpful for all students and may be our final opportunity to demonstrate that mathematics can make sense and be useful.

Hacker and I share an admiration for Lynn Steen and all that he has done to promote quantitative literacy, but there is one line of argument that Hacker picks up from Steen and then distorts beyond all recognition. In Achieving Quantitative Literacy: An Urgent Challenge for Higher Education [5], Steen expands on the problems inherent in an expectation that all students should be pushed down a track that is heading toward calculus. He despairs of the reluctance of many university mathematics departments to ease up on a graduation requirement of college algebra and places the blame on a select group of research mathematicians who insist that everyone should be "calculusintending."

There is an enormous difference between desiring to see all students learn and appreciate the modeling power inherent in the tools of Algebra 2-which, after all, is an eleventh-grade course for nonaccelerated students-and requiring all students to continue down the line of college 
algebra, precalculus, and calculus until they either succeed or run off the rails.

Steen is correct that there have been prominent mathematicians with considerable influence on their departments who have insisted on maintaining traditional requirements, but I see the greatest impediments to changing current practice lying on the high school side of the transition, where they are shaped by societal pressures. Despite the freedom-bordering on encouragement-within the Common Core's high school standards to use an integrated curriculum, which would be better placed to emphasize the practice standards, few districts have adopted this approach. The fault lies with the dominance of traditional curricular materials, the difficulty of getting a teacher corps that is stretched thin and subject to intense scrutiny to shift its instructional practices, and the fear of the public that any movement away from what was done in the past will jeopardize the prospects of their sons and daughters.

\section{The Real Dangers}

This is my greatest concern over the possible influence of this book: while it feeds the flames that are devouring the Common Core, our best hope for improving pre K-12 mathematics education, it will do nothing to change the underlying dynamic of what Steen truly and rightly feared, the funneling of everyone toward calculus.

Hacker describes the fraction of high school students who take calculus as "only" 17 percent. From the latest NCES data [4], 19 percent of the class of 2012, or roughly 750,000 students, had completed a course in calculus while in high school. That is huge. Only twice that many, 1.5 million, matriculate each fall as full-time students in a four-year undergraduate program. The numbers of students who take an AP Calculus exam is still growing at 5 percent per year, while the number of those who take it before grade 12 has reached 120,000, growing at almost 9 percent per year [2] (examples of exponential growth that I would hope all Americans could appreciate). Calculus in high school is now the accepted norm for those who intend to go to college. This is not the work of a cabal of "math mandarins." In fact, most mathematicians deplore this trend.

What drives it is the fact that the best single predictor of successful completion of college is enrollment in calculus while in high school [3]. This is only an observation of a high degree of correlation. Nevertheless, in this age of increased competition for access to the best colleges and universities, getting calculus onto one's high school transcript is highly desirable. Those who can accelerate do. Those who cannot but who enroll in calculus when they get to college find themselves, even if they are academically talented, at a considerable disadvantage as they compete against those for whom the material has some familiarity. When this handicap is piled on top of lower socioeconomic status, the obstacles to successful completion of a STEM degree can be enormous.
We live in a time of wide and widening societal inequities. If the mathematics of Algebra 2 is eliminated from the desired accomplishments of a high school graduate, it is not the children of college-educated parents who will take advantage of the easier route this reveals. I am cheered by the honest work of so many research mathematicians who are engaged in improving instruction across all levels while wrestling with the real problems of equity and access. The solutions are not simple. Beware of those who think they are.

\section{References}

[1] Pamela Burdman, Degrees of Freedom: Diversifying Math Requirements for College Readiness and Graduation, Report 1 of a 3-part series from Policy Analysis for California Education, April 2015. www.edpolicyinca.org/publications/ degrees-freedom-diversifying-math-requirementscollege-readiness-and-graduation-report-1-3-partseries

[2] College Board, AP Program Summary Reports. Available at https://research.collegeboard.org/programs/ap/data

[3] KASEY KLEPFER and Jim Hul, High School Rigor and Good Advice: Setting Up Students to Succeed, Center for Public Education of the National School Boards Association, October 2012. www. centerforpub7iceducation.org/MainMenu/Staffingstudents/High-school-rigor-and-goodadvice-Setting-up-students-to-succeed

[4] National Center for Education Statistics, High School Longitudinal Study of 2009 (HSLS:09), Institute of Education Science, US Department of Education.https://nces.ed.gov/ surveys/hs1s09/

[5] LYNN ARTHUR STEEN, Achieving Quantitative Literacy: An Urgent Challenge for Higher Education, MAA Notes \#62, Mathematical Association of America, Washington, DC, 2004.

\section{Photo Credit}

Photo of David Bressoud is courtesy of Jan Bressoud.

\section{ABOUT THE REVIEWER}

David Bressoud is former president of the Mathematical Association of America. In January 2017 he will take over the position of director of the Conference Board of the Mathematical Sciences.

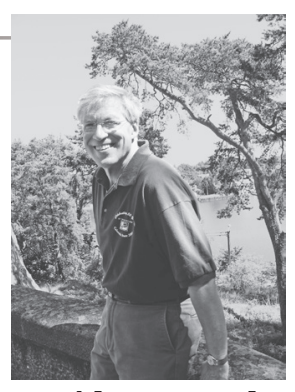

David Bressoud 